\title{
Knowledge, Attitude and Perceptions of Pregnant Women towards Caesarean Section among Antenatal Clinic Attendants in Cape Coast, Ghana
}

\author{
Article by James Kojo Prah ${ }^{1}$, Andreas Kudom², Obed Uwumbornyi Lasim³, \\ Emmanuel Kwasi $\mathrm{Abu}^{4}$ \\ ${ }^{1}$ University of Cape Coast Hospital, Cape Coast, Ghana \\ ${ }^{2}$ Department of Conservation Biology and Entomology, University of Cape Coast, \\ Cape Coast, Ghana. ${ }^{3}$ Department of Health Information Management, School of \\ Allied Health Sciences, University of Cape Coast, P.M.B, Cape Coast, Ghana. \\ ${ }^{4}$ Department of Optometry, School of Allied Health Sciences, University of Cape \\ Coast, Ghana.

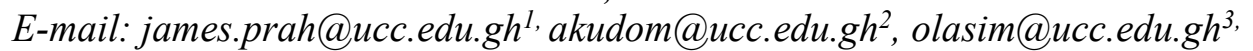 \\ eabu@ucc.edu.gh
}

\begin{abstract}
Over the years, caesarean section has become increasingly safe and remains one of the most commonly performed surgeries in obstetric practice worldwide. Even though there is an increased rate of Caesarean section in both developed and developing countries, some studies have suggested that African women have an aversion for it. We therefore set out to assess the knowledge, attitude and perceptions of Ghanaian women towards caesarean section.

A descriptive cross sectional study was conducted in the University of Cape Coast Hospital. A structured questionnaire was used to assess the knowledge, attitude and perception of 412 pregnant women towards caesarean section. Total knowledge was categorized as inadequate $(<50 \%)$ and adequate $(\geq 50 \%)$. All the 412 respondents were aware of caesarean section. There was, however, a low level of adequate knowledge (39.6\%) among the respondents. Majority of the women (94\%) preferred vaginal delivery to caesarean section as their primary mode of delivery. Although $40 \%$ perceived that most women undergoing CS may die, 95.7\% were willing to undergo the operation when indicated. However, $4.3 \%$ of the pregnant women would refuse the surgery even if indicated. Formal education $(p=0.018)$, parity $(p=0.035)$ and a previous experience of caesarean section $(p<0.0001)$ were significantly associated with adequacy of knowledge on caesarean section.

Even though there was a high awareness among the pregnant women, there was a low level of knowledge on caesarean section in our setting. Educational messages on caesarean section should be prepared to address especially issues on safety of the procedure and how post-operative pain is managed. Doctors should actively get involved in the education on caesarean section at the antenatal clinics, probably this will increase the knowledge of antenatal clinic attendants on CS.
\end{abstract}

Keywords: Caesarean section, awareness, knowledge, perception, University of Cape Coast Hospital, Ghana.

\section{Introduction}

Caesarean section (CS) is one of the most commonly performed surgical procedures in obstetrics and is certainly one of the oldest surgeries [6]. Probably the term caesarean was derived from the decree in Roman law, which made it mandatory for the operation to be performed on women dying during child birth, a term called lex caesarae [15]. This surgery has been reported throughout medical history and has steadily progressed from being fatal resulting in mortality for the mother or the child to being rendered safe for both mother and fetus during the $20^{\text {th }}$ century [15]. Caesarean section has greatly contributed to improved obstetric care throughout the world [18]. Even though there is an increased rate of Caesarean 
Texila International Journal of Public Health

Volume 5, Issue 1, Mar 2017

section in both developed and developing countries, there is a widely held belief that African women have an aversion for it $[4,14]$ and is perceived as a "curse" of an unfaithful woman [2]. It is therefore accepted reluctantly even in the face of obvious clinical indications. Previous studies conducted among Ghanaian women [1] indicated that majority of women prefer vaginal delivery to caesarean section and there are some who will not accept the surgery even if indicated. There is evidence to show that pregnant women who are knowledgeable about their condition are able to participate in shared decision-making [8]. With many more Ghanaian women now experiencing caesarean delivery [17], and about $97 \%$ of pregnant women now attending antenatal clinic [13] where education on caesarean section is expected to be given, it is expected that pregnant women in Ghana should be more knowledgeable on caesarean section than found in previous studies. We therefore set out to assess the knowledge, attitude and perceptions of Ghanaian women towards caesarean section.

\section{Methods}

\section{Study design and setting}

A descriptive cross sectional study was conducted in the University of Cape Coast Hospital, a primary health care institution located in Cape Coast, in the Central region of Ghana. It is an eighty (80) bed capacity hospital that serves the health care needs of students, staff of University of Cape Coast and people in Cape Coast and the neighbouring communities. Among the services provided by the hospital include antenatal care and emergency obstetric care to all pregnant women. About 1400 women deliver every year at the facility [21].

\section{Study population and sample}

The study population consisted of pregnant women of all ages attending the antenatal clinic of the University of Cape Coast Hospital from January to December 2015. A systematic sampling technique was used to recruit women into the study. Based on the average daily attendance at the clinic, a sampling interval of three was obtained. The first respondent was selected by balloting and picking a number between one and three. Every third woman in the queue waiting to be seen by the attending midwives was recruited into the study. Pregnant women who had visited the antenatal clinic at least twice in their current pregnancy irrespective of their delivery history were eligible for the study. Any woman who was interviewed had her antenatal card marked with a sign $(\sqrt{ })$ to avoid repeat of interview during her subsequent clinic attendance.

The sample size (n) was calculated from the formula $\mathrm{n}=\mathrm{z} \mathrm{pq} / \mathrm{d}^{2}$ where $\mathrm{z}$ is the normal standard deviation set at 1.96 which corresponds to $95 \%$ confidence interval, $d$ is the degree of accuracy desired set at 5\% in this study, (q=1-p), and $\mathrm{p}$ was $50 \%$. A minimum sample of 384 was therefore needed. This was adjusted to accommodate for a possible data loss of $10 \%$. The final minimum sample size was 422 .

\section{Research instrument}

A structured interviewer-administered questionnaire used in an earlier study [3] with slight modification was employed in this study to assess the pregnant women's knowledge, perception and attitudes towards caesarean sections. In addition, age, parity, marital status and educational background of respondents were collected. Nine questions were used to assess respondents' knowledge of caesarean section. Some of the questions used to assess their knowledge included whether they would be able to identify listed 4 common indications of CS, which were explained in simple English and in local dialect where applicable. A correctly identified indication of CS scored a quarter point. Also the women were asked if they knew of any risks or benefits of caesarean section. Any correct benefit or risk given scored a point. Respondents were asked about the usual length of hospital stay after surgery. The practice at the University of Cape Coast Hospital is to discharge women within a week after surgery. 
Most women are discharged on the third post operative day. Respondents were also asked whether a pregnant woman could have a vaginal delivery after a caesarean section. If a woman responded yes to the question she scored a point, a no response scored zero. A woman was categorized as having adequate knowledge if she scored at least $50 \%$. A respondent was considered to be aware of caesarean section if she had ever heard about it. Perceptions of respondents were assessed by their response to the statement that most women who have CS die. Their attitudes were assessed by their preferred mode of delivery and whether they would be willing to undergo the surgery if indicated. The pregnant women were also asked to suggest ways to make caesarean section more acceptable to them. The questionnaire were administered by trained student nurses who translated the questions into the local language in situations the pregnant women did not understand English.

\section{Data analyses}

Frequencies and percentages were computed using SPSS (Statistical package for social sciences) statistical software version 20.0. Association between level of knowledge on caesarean section and respondents' characteristics were carried out using a chi-square $\left(\chi^{2}\right)$ test. Characteristics with significant differences between groups by the $\chi^{2}$ test were included in a multivariate logistic regression analysis to predict their independent associations within the group. Statistical significance was set at $p<0.05$.

\section{Ethical consideration}

The study was approved by the Institutional Review Board of University of Cape Coast with reference number UCCIRB/EXT/2015/06. Written informed consent was obtained from the participants prior to being interviewed. Permission was also obtained from the authorities of University of Cape Coast Hospital before the study was conducted.

\section{Results}

Out of the 422 pregnant women invited into the study, 412 agreed to participate in the study. The ages of the respondents ranged from 15 to 41 years with a mean of $24.9 \pm 6.1$, parity ranged from 0 to 8 . Gravidity ranged from 1 to 12 with an average of $3.2 \pm 2.2$. The basic demographic data and obstetric history of respondents are shown in table 1.

All $412(100 \%)$ pregnant women had ever heard about caesarean section. With regards to respondents' knowledge about caesarean section 163 (39.6\%) had adequate knowledge with the remaining 249 (60.4\%) found to have inadequate knowledge. In the assessment of their knowledge on CS, only 185 (45\%) respondents could correctly identify one indication for the surgery. When asked to state one risk and one benefit they knew about CS, there were varied responses. When asked about the usual hospital stay after surgery, $181(43.9 \%)$ were able to say that women are discharged within a week after surgery. Only $173(42 \%)$ of respondents knew that a woman could deliver vaginally after a caesarean section. Participants' level of knowledge about CS was significantly associated with parity $(\mathrm{p}=0.035)$, past experience of CS $(p<0.0001)$ and level of formal education $(p=0.018)$. With regards to parity, only women who had at least three deliveries had statistically significant level of knowledge when compared to those who had never given birth $(\mathrm{O} R=2.1, \mathrm{p}=0.004)$ while women who had given birth once or twice only having no significant level of knowledge (Table 2). Women who had undergone previous CS where 8 times more likely to have adequate knowledge than women who had no previous experience of CS. By comparing with participants with no formal education, individuals who had basic, secondary and tertiary education were more likely to have adequate level of knowledge about CS ( $\mathrm{p}=0.02,0.01$ and 0.05 respectively). The age of the pregnant woman $(\mathrm{p}=0.828)$, her occupation $(\mathrm{p}=0.328)$ and her gravidity $(\mathrm{p}=0.713)$ were not significantly associated with her adequacy of knowledge on caesarean section.

On their preferred mode of delivery, 387 (94\%) preferred vaginal delivery to CS, $16(4 \%)$ preferred CS as their primary mode of delivery and the remaining $8(2 \%)$ were undecided. 
Texila International Journal of Public Health

Volume 5, Issue 1, Mar 2017

Reasons given for choosing vaginal delivery as the preferred mode of delivery included: it is the safest $(89 \%)$, it is natural $(90 \%)$, less pain after delivery (63\%), and early discharge from hospital $(24 \%)$. The main reasons given by the pregnant women who preferred CS were avoidance of labour pains (49\%), fear of having episiotomies (54.6\%), safer route of delivery $(24.3 \%)$, and avoidance of emergency CS (11.8\%). Majority $390(94.6 \%)$ of the pregnant women, however, said they would agree to the operation if it was indicated. A minority $18(4.3 \%)$ said they would not agree to undergo the procedure even when indicated. The rest were undecided.

Of the 412 women interviewed, $165(40 \%)$ perceived caesarean section as being dangerous to the mother as they agreed with the statement that most women who have CS die; 232 (56.3\%) did not believe that most women who have CS die, whilst 15 (3.7\%) could not give an opinion on the statement. Among the 412 respondents, $23(6.1 \%)$ had had a previous caesarean section. Of these, $18(78.3 \%)$ said CS was their preferred mode of delivery, $3(13.0 \%)$ preferred vaginal delivery whilst $2(8.7 \%)$ were undecided. All $23(100 \%)$ were willing to undergo another CS if indicated.

The main source of information about CS among the respondents was the media (55.7\%), family and friends $(12.3 \%)$ and antenatal clinic (32\%). With regards to the level of education on CS at the antenatal clinic, $288(70 \%)$ rated it as good whilst $124(30 \%)$ said it was bad. When asked to suggest ways to make CS more acceptable to pregnant women, all 412 respondents were of the opinion that more education on CS should be done during antenatal clinics. Other responses were: doctors should be part of the education on CS (94.9(\%), CS should be made less painful (48.5 (\%) and the use of evidence-based leaflets and videos at the antenatal clinics $(5.3 \%)$.

\section{Discussion}

All of the pregnant women surveyed were aware of caesarean section as a mode of delivery. This level of awareness among pregnant women found in this study is higher than that found in some previous studies conducted in Ghana [1] and Nigeria [3]. The difference could be due to the difference in study designs, study population and the years between the studies. Despite this high awareness, only $39.5 \%$ of the respondents had adequate knowledge on CS. This finding is similar to a previous study among Nigerian women [3]. This might be because as much as $68 \%$ of the pregnant women in this study said their main sources of information on CS were the media and from family and friends which are usually unreliable sources unlike knowledge gained at antenatal clinics. Formal education was significantly associated with knowledge of respondents on CS. This is probably because the educated women could easily assess the media including the internet for any information they need on CS. The multivariate logistic regression analysis revealed that the higher a respondent's level of education did not necessarily mean a higher adequacy of knowledge on CS compared to those with lower levels of formal education. This suggests that some of the women even though highly educated it does not necessarily mean they have adequate knowledge on CS. Thus, there is a need for all pregnant women irrespective of level of formal education to seek knowledge about caesarean section from authentic and reliable sources. The study revealed that a previous experience of CS was highly associated with adequate knowledge on CS. This could probably be due to the likelihood that women who had CS in the past had received adequate pre-operative information on the surgery coupled with the knowledge they might have received during their antenatal clinics as well as their own personal experiences. The finding that only women who had at least three deliveries had statistically significant level of knowledge when compared to those who had never given birth shows that probably pregnant women in our setting do not receive adequate information on CS when they attend the antenatal clinics for any given pregnancy and would therefore need at least three pregnancies to consolidate their knowledge about CS. Health educators at the antenatal clinics should therefore give more attention to education on CS so that a pregnant woman could become adequately knowledgeable on CS after completing antenatal visits for only one pregnancy. An 
overwhelming majority of the respondents 387 (94\%) preferred vaginal delivery to caesarean section. This is consistent with findings from other studies in different populations $[7,20]$. Despite the high preference for vaginal delivery, it is interesting to note that $97.5 \%$ of the respondents were willing to have CS when indicated. Similar results have been reported in some studies where the acceptability of the operation was found to be $85 \%$ in Nigeria [4] and $90.5 \%$ in Ghana [1]. Compared to a previous study in Ghana [1] which reported that $6 \%$ of those surveyed would not accept CS even if indicated, it can be inferred that many more Ghanaian women are now accepting CS as a safe alternative to vaginal delivery. This may be because with the increasing rise in caesarean section rates worldwide, many more women who have successfully undergone the surgery tell their stories thus allaying the fears of others about the surgery. The finding is also contrary to the widely held belief that African women have an aversion for CS [9, 12, 19]. On their perception about CS, $40 \%$ of women in the present study think that most women who undergo CS die. This finding means that a significant number of pregnant women still consider CS very dangerous and this must be adequately addressed through education. Although studies have reported increased risk of maternal death for CS as compared to vaginal delivery [10,11], CS remains one of the most commonly performed surgical operation in obstetric practice all over the world [4]. Over the years, it has become relatively very safe because of improved surgical technique, better anaesthesia, safe blood transfusion and the use of highly effective antibiotics [5]. All the women in the study wanted education on CS to be included in antenatal health education topics. Since $124(30 \%)$ of the pregnant women rated the level of education on CS at the antenatal level as bad, effort should be made to ensure that education about CS is done at almost every clinic session. This will increase the knowledge level of the pregnant women on the surgery and avoid their over reliance on the media, family and friends which are unreliable sources of information. Among strategies suggested by the pregnant women to improve acceptability of CS, 391 (94.9\%) of them wanted doctors' involvement in the education process. Studies conducted in different populations worldwide found that in most cases only midwives are the educators at antenatal clinics [16]. It is clear from the findings in this survey that the pregnant women want this practice to change. A small number of respondents $(5.3 \%)$ suggested the use of evidence-based leaflets and videos. This suggestion is important because in recent years there has been considerable interest in the potential for transmitting information to clients using resources such as digital video discs (DVDs), compact disc read-only memory (CD ROMs), evidence-based leaflets, and posters that are less expensive than health practitioners' time [16]. This should, however, not replace the face to face interactive sessions that take place at the antenatal clinics. A study [22] found that women prefer receiving information from health care professionals over and above any other source. Since most of the pregnant women were concerned about the safety and post operative pain management, the content of educational messages on CS should address these issues effectively.

\section{Limitations of study}

One of the limitations of this study was that it involved only women excluding the men who are important stakeholders in decision making on caesarean sections. Also the study did not explore the reasons why some women in our setting would not give consent for the surgery even when indicated. The social, cultural and economic states of the women which may influence their knowledge, attitude and practices towards caesarean section were not explored. Further studies would have to be done in our setting to assess the adequacy of preoperative counselling and the effectiveness of other forms of education such as the use of videos and leaflets and posters to the pregnant women.

\section{Conclusion}

Although all the women were aware of CS there was still a low level of knowledge on the surgery in our setting. Whilst majority of them were willing to undergo the surgery when 
Texila International Journal of Public Health

Volume 5, Issue 1, Mar 2017

necessary, some women would still not accept to undergo CS under any circumstances. This brings to light the need to intensify education on CS at the antenatal clinics with a look at the content of such educational messages aimed at addressing the fears being entertained by women about the surgery and also further studies conducted to ascertain the reasons why some women will not accept the surgery even if indicated. Also doctors should actively get involved in the education of pregnant women. Other resources such as DVDs and leaflets could be employed to augment what is done at the antenatal clinics. All these will possibly help pregnant women to be well informed about caesarean section which could be lifesaving and thus be in better positions to make informed decisions about the procedure.

\section{Acknowledgements}

The authors are grateful to the staff of the antenatal clinic and management of the University of Cape Coast Hospital for making this study possible.

\section{References}

[1]. Adageba, R.K., Danso, K.A., Adusu-Donkor A., \& Ankobea-Kokroe F. (2008). Awareness and perception of and attitude towards caesarean delivery among antenatal. Ghana Med J. 42: 137 - 140.

[2]. Adeoye-Sunday, I., \& Kalu, C.A. (2011). Pregnant Nigerian women's view of caesarean section. Niger J ClinPract. 14: $276-9$.

[3]. Ashimi, A.O., Amole, T.G., \& Aliyu, L.D. (2013). Knowledge and attitude of pregnant women to caesarean section in a semi-urban community in northwest Nigeria. J West AfrColl Surg. 3(2): 46-61

[4]. Awoyinka, B.S., Ayinde, O.A., \& Omigbodum, O.A. (2006). Acceptability of caesarean delivery to antenatal patients in a tertiary health facility in South West Nigeria. J OBstetGynaecol. 26(3); 20810

[5]. Aziken, M., Omo-Aghoja, L., \& Okonofua, F. (2007). Perceptions and attitudes of pregnant women towards caesarean section in urban Nigeria. ActaObstetGynecol Scand. 86(1):42-47.

[6]. Chaser, M.J. (1956). Caesarea section, sterilization and hysterectomy. In: Munro Kerr's Operative obstetrics, BallierreTindall and Cox, London, 1956; p.539

[7]. Chong, E.S.Y, \& Mongelli, M. (2003). Attitudes of Singapore women towards caesarean and vaginal deliveries. Int J Gynaecol Obstet. 80:189-194.

[8]. Coulter, A., Parsons, S., \& Askham, J. (2008). Where Are The Patients In Decision- Making About Their Own Care? Copenhagen, Denmark: WHO Regional Office For Europe;2008

[9]. Danso, K., Schwandt, H., Turpin, C., Seffah, J., Samba, A., \& Hindin, M. (2009). Preference of Ghanaian women for vaginal or caesarean delivery postpartum. Ghana MedJ 43(1):29-33.

[10]. Deneux-Tharau, C., Carmona, E., Bouvier-Colle, M.H., \& Breart ,G. (2006). Postpartum maternal mortality and caesarean delivery. ObstetGynaecol. 108(3 pt1):541-548.

[11]. Devendra, K., \& Arulkumaran, S. (2003). Should doctors perform elective caesarean section on request? Ann Acad Med Singapore. 32(5):577-581.

[12]. Etuk, S.J., Asuquo, E.E.J., \& Ekanem, A.D. (1999). Maternal mortality following Caesarean section at the University of Teaching Hospital, Calabar, Nigeria. Niger J Med. 8: 62 - 65 .

[13]. Ghana Demographic Health Survey, 2014.

[14]. Ilesanmi, A.O., Odukogbe, A., \& Olaleye, D.O. (1997). Vaginal delivery after one previous Caesarean section in Nigerian women. J Obstet Gynecol. 17: 139 -41.

[15]. Kwawukume, E.Y. Caesarean section. In: Kwawukume EY, Emuveyan EE, editors. Comprehensive Obstetrics in the Tropics. Dansoman: Asante and Hittscher Printing Press; 2002. p. 321-329

[16]. Mary, L.N. Information Giving and Education In Pregnancy: A Review Of Quanlitative Studies. J Perinat Educ. 2009 Fall;18(4):21-30

[17]. Multiple Indicator Survey, Ghana Statistical Services, 2011

[18]. Nkwo, O.P., \& Onah, H.E. (2002). Feasibility of reducing Caesarean section rate of the University of Nigeria Teaching Hospital, Enugu-Nigeria. Trop J ObstetGynaecol. 19 (2): 86-9.

[19]. Orji, E.O., Ogunniyi, S.O., \& Onwudiegwu, U. (2003). Beliefs and perception of pregnant women at Ilesa about Caesarean section. Trop J ObstetGynaecol. 20: 141 -143. 
Texila International Journal of Public Health

Volume 5, Issue 1, Mar 2017

[20]. Osis, M.J.D., Padua, K.S., Duarte, G.A., Souza, T.R., \& Faundes, A. (2001). The opinion of Brazilian women regarding vaginal labour and caesarean section. Int J Gynaecol Obstet 75:S59-S66.

[21]. Prah, J., Ameyaw, E.O., Afoakwah, R., \& Kudom, A. (2016). Factors affecting birth weight in Cape Coast, Ghana. Int J ReprodContraceptObstetGynecol. 5:1536-9.

[22]. Risica, P.M., \& Phipps, M.G. (2004). Educational preferences in a prenatal clinic. Int J Childbirth Educ 21(4):4-7.

Tables

Table 1. Basic demographic data and obstetric history of respondents

\begin{tabular}{ll}
\hline Characteristic & $\mathrm{n}(\%)$ \\
\hline Age group & $79(19.2)$ \\
$15-19$ & $143(34.8)$ \\
$20-24$ & $111(27.0)$ \\
$25-29$ & $32(7.8)$ \\
$30-34$ & $47(11.2)$ \\
$>35$ & \\
\hline Parity & $130(31.6)$ \\
0 & $89(21.6)$ \\
1 & $33(8.0)$ \\
2 & $160(38.8)$ \\
$\geq 3$ & \\
Previous CS experience & $28(6.8)$ \\
Yes & $388(93.2)$ \\
No & \\
Marital status & $400(97.1)$ \\
Married/cohabiting & $12(2.9)$ \\
Single & \\
Gravidity & $85(20.6)$ \\
1 & $150(36.4)$ \\
2 & $93(22.6)$ \\
3 & $84(20.4)$ \\
$\geq 4$ & $62(15.0)$ \\
\hline Occupation & $350(85.0)$ \\
Employed & $20(4.9)$ \\
Unemployed & $116(28.2)$ \\
Formal education & $202(49.0)$ \\
None & $74(17.9)$ \\
Basic & \\
Secondary & \\
Tertiary & \\
\hline &
\end{tabular}

Table 2: Multivariate logistic regression analysis between participants' knowledge about CS and demographic characteristics

\begin{tabular}{llll}
\hline Characteristic & $\begin{array}{l}\text { Number with } \\
\text { adequate } \\
\text { knowledge } \mathrm{n}(\%)\end{array}$ & OR $(95 \% \mathrm{CI})$ & $\mathrm{p}$-value \\
\hline Parity $(\mathrm{n}=412)$ & & & \\
0 & $39(23.9)$ & Reference & - \\
1 & $36(22.1)$ & $1.6(0.9-2.8)$ & 0.11 \\
2 & $13(8.0)$ & $1.5 .(0.7-3.4)$ & 0.30 \\
$\geq 3$ & $75(46.0)$ & $2.1(1.3-3.4)$ & 0.004
\end{tabular}


Texila International Journal of Public Health Volume 5, Issue 1, Mar 2017

\begin{tabular}{|c|c|c|c|}
\hline \multicolumn{4}{|c|}{$\begin{array}{l}\text { Previous CS } \\
(\mathrm{n}=163)\end{array}$} \\
\hline No & $140(85.9)$ & Reference & - \\
\hline Yes & $23(14.1)$ & $8.0(3.0-21.6)$ & $<0.001$ \\
\hline \multicolumn{4}{|c|}{$\begin{array}{l}\text { Formal Education } \\
(\mathrm{n}=412)\end{array}$} \\
\hline None & $2(1.2)$ & Reference & - \\
\hline Basic & $47(28.8)$ & $6.1(1.4-27.7)$ & 0.02 \\
\hline Secondary & $89(54.60)$ & $7.1(1.6-31.4)$ & 0.01 \\
\hline Tertiary & $25(15.4)$ & $4.6(1.0-21.4)$ & 0.05 \\
\hline
\end{tabular}

$\mathrm{OR}$, odds ratio; $\mathrm{CI}$, confidence interval 